\title{
Prevention of type 1 diabetes
}

\author{
Diane K. Wherrett, MD FRCPC and Denis Daneman, MBBCh FRCPC \\ Division of Endocrinology, Department of Pediatrics, the Hospital for Sick Children and University \\ of Toronto, Toronto, Canada.
}

\section{SYNOPSIS}

Prevention of loss of $\beta$ cells in type 1 diabetes is a major goal of current research. Knowledge of the genetic susceptibility, the increasing ability to predict who may be at risk, the recognition of the potential clinical impact of residual insulin secretion after diagnosis and the development of new immunomodulatory agents have supported an increasing number of clinical trials to prevent $\beta$ cell loss. Interventions can be targeted at three stages: prior to the development of autoimmunity - primary prevention, after autoimmunity is recognized - secondary prevention or after diagnosis when significant numbers of $\beta$ cells remain- tertiary prevention. Thus far a number of agents show promise when given shortly after diagnosis but no interventions prior to diagnosis have shown benefit. Knowledge in this area has grown quickly in recent years and will continue to grow rapidly with a number of international collaborative efforts underway.

\section{Keywords}

Type 1 diabetes; Autoimmunity; Prevention; Immunology; Genetics; Clinical; Trials

\section{INTRODUCTION}

Type 1 diabetes is an autoimmune disease in which the $\beta$ cells of the pancreatic islets are destroyed rendering the individual increasingly incapable of mounting a normal insulin response to ingested nutrients ${ }^{1,2}$. In the early 1980's Eisenbarth enunciated the main phases in the pathogenesis of type 1 diabetes (figure 1), a framework which continues to be useful in considering approaches to the prevention or cure of this disorder ${ }^{2}$ :

1. susceptibility to T1D is inherited through a series of genes, the most important of which relate to the HLA class II-locus on chromosome 6, with lesser contribution from a number of others, including the insulin gene, CTLA4 and others (see below). Susceptibility genes are essential, but insufficient in explaining the immune pathogenesis of TID, i.e. the majority of individuals with these susceptibility genes never develop the disorder.

\footnotetext{
(c) 2009 Elsevier Inc. All rights reserved.

Correspondence: Dr. Denis Daneman The Hospital for Sick Children 555 University Avenue Toronto, Ontario M5G 1X8 Canada Phone: 416 813-6122 Fax: 416 813-7479 denis.daneman@sickkids.ca. Co-author contact information: Dr. Diane Wherrett diane.wherrett@sickkids.ca The Hospital for Sick Children 555 University Avenue Toronto, Ontario M5G 1X8 Canada Phone: 416 813-8159 Fax: 416 813-6304.

Publisher's Disclaimer: This is a PDF file of an unedited manuscript that has been accepted for publication. As a service to our customers we are providing this early version of the manuscript. The manuscript will undergo copyediting, typesetting, and review of the resulting proof before it is published in its final citable form. Please note that during the production process errors may be discovered which could affect the content, and all legal disclaimers that apply to the journal pertain.
} 
2. exposure to one or more environmental trigger(s) alters the immune system in such a way that susceptibility is converted to pathophysiology and destruction of $\beta$ cells begins. Despite intensive searches for environmental triggers, the number of candidates being assessed in clinical trials remains quite small, e.g. cow's milk proteins, relative lack of vitamin D and supplementation with omega 3 fatty $\operatorname{acids}^{3-7}$

3. while attack on the $\beta$ cells is mediated in large part by $\mathrm{T}$ cells, it is the presence of humoral (B cell) markers that punctuates the next phase: normal glucose homeostasis in the presence of one or more T1D-specific autoantibodies, ICA512/IA-2, IAA and GAD are the main ones available for measurement. The progression to clinical TID is highly predictable based on the number of antibodies present ${ }^{8}$.

4. the earliest metabolic abnormality detected is loss of first phase insulin secretion in response to an intravenous glucose load. Glucose levels remain normal in response to meal challenges at this stage. Later, impaired glucose tolerance develops. This leads inexorably to the next phases of clinical diabetes.

5. when $\beta$ cell mass is significantly decreased, insulin secretory capacity is damaged to such a degree that it is no longer sufficient to maintain normoglycemia and clinical diabetes supervenes. This phase includes the honeymoon or remission period of T1D when some $\beta$ cell function is retained, also referred to as the C-peptide positive phase of clinical diabetes.

6. finally, in most, but not all, individuals with T1D $\beta$ cell function is eventually completely lost and C-peptide levels become undetectable. There is a relationship between the presence of diabetic ketoacidosis at disease onset and the rapidity of loss of $\beta$ cells, as well as between the presence of residual $\beta$ cell function and the ability to achieve and maintain better metabolic control.

A few additional facts are important in considering targets for prevention or early intervention in the pathogenesis of $\mathrm{T}^{\mathrm{D}} \mathrm{D}^{9}$. First, the incidence of this condition is increasing by $2-5 \%$ per year worldwide, especially in the youngest age group $(<5 \text { years of age })^{10}$. Second, there is enormous variability in incidence of T1D around the world, from $<4 / 100,000$ population under age 14/year in much of Africa and Asia to over 20 in Canada, Australia and parts of Europe, with the highest incidence being in Finland (>50/100,000 population reported in 2008) ${ }^{11}$. Third, migrating populations take on the increased incidence of their new countries relatively rapidly, e.g. Asian immigrants to the United Kingdom, immigrants from the Horn of Africa (Somalia, Eritrea and Ethiopia) to North America ${ }^{12}$. Fourth, there is evidence that genetically similar populations may have enormously dissimilar incidence rates, e.g. Finland and Russian Karelia $^{13}$. These factors speak strongly to an important role for environmental factors in the etiology of T1D since genetic drift cannot explain the rapidity of these changes. Furthermore, where incidence is increasing most rapidly, the contribution of genetic susceptibility appears to be less ${ }^{14}$.

\section{Genetics of Type 1 Diabetes}

T1D is 15 times more common in siblings of those with T1D, with the general population prevalence of approximately $0.4 \%$ and the sibling prevalence of approximately $6 \%{ }^{15}$. Genes located within the HLA class II region on chromosome 6p21 account for approximately 50\% of genetic risk for T1D ${ }^{16}, 17$. Haplotypes associated with T1D include: DQ2 (DQB1*0201DQA $1 * 0501-\mathrm{DRB} 1 * 03)$ and DQ8 (DQB $1 * 0302-\mathrm{DQA} 1 * 0301-\mathrm{DRB} 1 * 04)^{18}$. Other HLA alleles, DQA $1 * 0102$, DQB $1 * 0602$, are protective for $\mathrm{T}^{*} \mathrm{D}^{19}$. A region in the regulatory region of the insulin gene (INS) locus has also been shown to provide approximately $10 \%$ of the genetic susceptibility for $\mathrm{T}^{1} \mathrm{D}^{18}$. A polymorphism in the PTPN22 (protein tyrosine phosphatase non-receptor type 22) gene has been found to be associated with a number of autoimmune 
diseases, including type 1 diabetes and autoimmune thyroid disease ${ }^{18}$. The gene product, a lymphoid tyrosine phosphatase, LYP, inhibits the T-cell receptor signaling pathway. Polymorphisms in the cytotoxic T lymphocyte-associated gene (CTLA-4) are also associated with T1D and a number of other autoimmune diseases ${ }^{20}$. Signaling through CTA4 is critical in the down-regulation of $\mathrm{T}$ cell responses. A total of ten genes/regions have been confirmed to be associated with T1D. Identification of these genes provides investigative targets for new understanding of disease pathogenesis.

While there have been important discoveries with respect to the genetics of T1D and the autoimmune processes involved, little progress has been made in identifying highly specific environmental factors pivotal in triggering this disorder. Two hypotheses remain prominent in this respect: the Hygiene Hypothesis which suggests that in modern society, the lack of exposure to pathogens early in life prevents the genetically predisposed immune system from protecting itself from autoimmune phenomena, while the Accelerator Hypothesis suggests that increasing worldwide obesity stresses the susceptible cell thereby triggering its early demise $^{21-27}$. The only environmental trigger undergoing active investigation is the possibility that early exposure to cow's milk proteins may be important in T1D pathogenesis (or conversely that breast milk protects against triggering of the autoimmune attack). The effort to better identify environmental factors is currently being led by the Environmental Determinants of Diabetes in the Young (TEDDY) Study. This study will enroll 7,800 infants with high risk HLA genotypes for serial assessment of islet autoimmunity and environmental exposures such as diet, infectious diseases and immunizations ${ }^{28}$. Enrollment of the cohort should be complete by the end of 2009 .

\section{Targets for prevention or early intervention}

Prevention of T1D would require interventions aimed at (i) avoiding exposure to the environmental trigger(s) early in life - Primary Prevention; (ii) interfering with the autoimmune cascade that occurs during $\beta$ cell destruction - Secondary Prevention or Intervention; or (iii) halting or reversing $\beta$ cell loss after clinical presentation of T1D - Tertiary Intervention. Once full blown clinical T1D has developed, the only approach to disease reversal would be physiological insulin replacement using either an artificial pancreas or $\beta$ cell replacement with islet or pancreatic transplantation. In the future, T1D is seen as one of the disorders most likely to be amenable to stem cell therapy.

\section{PRIMARY PREVENTION}

An environmental role in the pathophysiology of T1D is supported by number of factors: low concordance rate of the disorder in identical twins (20-50\%); very different incidence rates in populations of similar genetic make-up but significant socioeconomic differences (e.g. Finland and Russian Karelia); and rapid shifts in incidence both in different areas of the world as well as with population migrations. The specific environmental factors involved remain largely unproven, although both epidemiological and animal-model data suggest a potential role for dietary factors, and more specifically two, namely early exposure to cow's milk and relatively low vitamin D concentrations, with much more data pointing to a role for cow's milk proteins $^{3-7,29}$.

There are good data to indicate that the pathogenetic processes leading to T1D may begin very early in life. This, together with the animal-model and epidemiological data, has provided the impetus to evaluate carefully the role of weaning diets on the evolution of T1D, and most especially the role of early exposure to cow's milk proteins. A more detailed description of the supporting data is beyond the scope of this paper but can be found in references ${ }^{3-7,} 29$. 


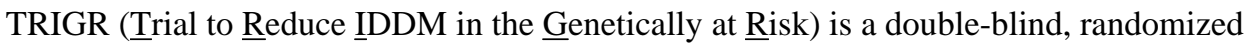
placebo-controlled trial that will definitively test the hypothesis that weaning to a hydrolyzed diet, and thereby avoiding early cow's milk protein exposure, will protect high risk newborns from initiation of the $\beta$ cell specific autoimmune response and therefore prevent T1D ${ }^{30}$. This international multicenter study is powered to meet these objectives. The recruitment of high risk newborns allows concentration of the subjects more likely to develop T1D: subjects are recruited if their mother, father or sibling has T1D, and then screened for high risk HLA haplotypes. If positive, the neonates are randomly assigned to one of two groups: feeding up to 6-8 months of age with either a regular cow's milk-based formula, versus an extensively hydrolyzed cow's milk formula. Breast feeding is encouraged and noted as a potential confounder in the study. The study design is shown in Figure 2 and inclusion and exclusion criteria are listed below:

Newborns with a first-degree relative (i.e. mother/father/sibling) with TID are eligible.

Inclusion criteria:

1. the infant has one of the following genotypes:

a. HLA-DQB $1 * 0302 / \mathrm{DQA} 1 * 05-\mathrm{DQB} 1 * 02$

b. HLA- DQB $1 * 0302 / x$ (i.e. not DQB $1 * 02$, DQB $1 * 0301$ or DQB $1 * 0602$ )

c. HLA-DQA $1 * 05-\mathrm{DQB} 1 * 02 / \mathrm{y}$ (not DQA $1 * 0201-\mathrm{DQB} 1 * 02$, DQB $1 * 001$, DQB $1 * 0602 / 3$ )

d. HLA-DQA $1 * 03-\mathrm{DQB} 1 * 02 / \mathrm{y}$ (excluding same ones as in c. above)

2. Family able to provide written informed consent

Exclusion criteria:

1. An older sibling in TRIGR intervention

2. Multiple gestation

3. Parents unwilling/unable to give study formula

4. Newborn has recognizable severe illness

5. Inability of family to participate in the study

6. Infant received any formula other than Nutramigen prior to randomization

7. Infant older than 7 days at randomization

8. No HLA sample prior to 8 days of age.

The major outcome for the first phase of TRIGR is the frequency of T1D-associated autoantibodies and/or development of diabetes by age 6 years. The outcome of the second phase is the manifestation of diabetes by age 10 years according to standard criteria. This latter is obviously the more definitive outcome, although the intervention may delay rather than prevent the manifestation of T1D. This latter outcome would be masked by the final outcome being measured at age $10^{30}$. Screening for TRIGR began in May 2002, with final enrollment completed by September 2006. Thus, the antibody data will be available in 2012, and the T1D outcomes in 2016.

A double-blind placebo-controlled pilot study of omega 3 fatty acid supplementation with Docosahexaenoic acid (DHA) to prevent islet autoimmunity is being carried out by the Type 1 Diabetes TrialNet study group ${ }^{31}$. Diets higher in omega-3 fatty acids have been associated with lower risk of islet autoimmunity and diabetes ${ }^{32}$. DHA is known to have an anti- 
inflammatory effect. Entry to the study was during the third trimester or during the first 5 months of life in pregnant mothers/infants with a first-degree relative with T1D. At birth, HLA typing was done on cord blood and those with high risk alleles were eligible. Enrollment of 97 infants is complete with results of compliance, levels of whole blood DHA and inflammatory markers expected in late 2009.

A feasibility study, BABYDIET, of delay of introduction of gluten to prevent islet autoimmunity in infants with a first degree relative with T1D and high risk HLA genotypes is underway in Germany ${ }^{33}$. The timing of introduction of cereals to infants has been associated with diabetes ${ }^{34}$. Infants were randomized to introduction of gluten at 6 or 12 months with follow-up every 3 months to 36 months of age.

Vitamin D is increasingly recognized as an immunomodulator. Its effects on the immune system are multifold:

1. in acquired immunity, Vitamin $D$ induces an inhibitory response through reduction of $\mathrm{T}$ cell proliferation, interleukin 2 and interferon $\gamma$ production and CD8-mediated cytotoxicity. This results in a reduction of $\mathrm{T}$ helper 1 responses and a promotion of $\mathrm{T}$ helper 2 responses. In this way it improves T-regulatory forces and provides for a more balanced and tolerogenic milieu ${ }^{35}$;

2. in the innate immune system, Vitamin D inhibits dendritic cell function at multiple levels and mediates antibacterial actions through cathelicidin and the toll-like receptor 4 pathway ${ }^{35}$.

Animal models show that treatment with $1,25(\mathrm{OH})_{2}$ Vitamin $\mathrm{D}_{3}$ or its analogues can prevent T1D and other immune-modulated disorders ${ }^{35}$. Furthermore, there are data in humans which suggest that Vitamin D may also play a role. For example, the incidence of T1D increases with increasing distance from the equator suggesting a role for sun exposure. A recently published meta-analysis examined the association between vitamin D supplementation and the development of type 1 diabetes. It found a significantly reduced risk of developing type 1 diabetes in those supplemented with vitamin $\mathrm{D}(\mathrm{OR} 0.71)^{36}$. A definitive prospective study on the effect of vitamin D supplementation on the development of diabetes remains to be performed.

\section{SECONDARY PREVENTION}

The goal of secondary prevention studies is to prevent the progression of islet destruction that will lead to overt T1D. In order to carry out these studies, reliable prediction models are required. Current prediction models utilize combinations of autoantibodies and measures of glucose tolerance to stratify risk. It is known that autoantibodies typically develop years before onset of diabetes. These antibodies include islet cell antibodies (ICA), insulin autoantibodies (IAA), and antibodies to glutamic acid decarboxylase (GAD), tyrosine phosphatase (IA-2/ ICA512) and zinc transporter $8(\mathrm{ZnT} 8)^{37}$. The presence of two or more antibodies indicates a significantly increased risk of developing diabetes with some studies reporting increasing risk with increasing number of antibodies. One study showed that relatives with 1 or more antibodies had a $25 \%$ risk of disease development over a 5 year period, 2 or more antibodies had a 39\% risk of developing T1D within 3 years and those with 3 or more antibodies had a $75 \%$ risk of disease development over a 5 year period. ${ }^{38}$. As beta cell destruction progresses, subclinical glucose abnormalities develop. Evidence from the Diabetes Prevention Trial-Type 1 (DPT-1), showed that both fasting and 2 hour glucose levels rise gradually as stimulated Cpeptide levels slowly decline in the 30 months prior to diagnosis ${ }^{39}$. Type 1 Diabetes TrialNet, an international study group carrying out research into the prevention and early treatment of type 1 diabetes is running a large longitudinal observational study of relatives of those with type 1 diabetes to further improve prediction ${ }^{40}$. 
Three large multi-center trials of diabetes prevention in autoantibody positive subjects have been completed. The European Nicotinamide Diabetes Intervention Trial (ENDIT), used nicotinamide as a secondary preventative agent. Despite promising animal data and evidence from a previous study, Nicotinamide administration in ICA-positive relatives did not delay the onset of T1D when compared to placebo. ${ }^{41}$ In the Diabetes Prevention Trial-Type 1 (DPT-1), insulin was given either orally or parenterally to alter the immune response toward insulin ${ }^{42}$, ${ }^{43}$. Subjects at high risk (greater than $50 \%$ over 5 years with ICA positive with low first phase insulin response) of developing T1D received parenteral insulin. Those at moderate risk (25 to $50 \%$ over 5 years with ICA and IAA but normal first phase insulin secretion) received insulin orally. The primary analysis of both arms of DPT-1 did not show an effect on the development of T1D ${ }^{42}$. Post hoc analysis of DPT-1 oral insulin arm, however, suggested a beneficial effect in the subgroup with high titers of insulin autoantibodies ${ }^{43}$. The results of the Type 1 Diabetes Prediction and Prevention Study (DIPP) were recently published ${ }^{44}$. In this study, newborns from the general population and siblings of those with diabetes had HLA genotyping done at birth. Those with two or more islet antibodies and high risk HLA alleles were treated with nasal insulin or placebo. The study was stopped early as the treatment had no effect. The results of these studies, though disappointing, demonstrate that large scale prevention studies are feasible and provide significant insight into planning for future studies.

There are currently three diabetes prevention trials underway. The first is the Type 1 Diabetes TrialNet study, "Oral Insulin For Prevention of Diabetes In Relatives at Risk for Type 1 Diabetes Mellitus". This study is further investigating the suggestion of benefit of oral insulin in seen the DPT-1 subjects with high IAA titers. Subjects have insulin autoantibodies and one of ICA, GAD antibodies or ICA512 antibodies. The study intervention is oral insulin $7.5 \mathrm{mg}$ daily or placebo for the study's duration with the endpoint the development of diabetes. Recruitment began in 2007. The Pre-POINT trial is an international multicenter study that is examining intervention with both nasal and oral insulin in children age 18 months to 7 years who have a sibling or two or more relatives with $\mathrm{T}_{1} \mathrm{D}^{45}$. These children also have high risk HLA alleles but no islet autoantibodies. The effects of four doses of both oral and nasal insulin are being studied to determine whether autoimmunity will be affected. If the study is successful, a larger trial is planned.

The Intranasal Insulin Trial (INIT) is based in Australia and New Zealand and is assessing the effect of intranasal insulin in first and second degree relatives ages 4 to 30 years who are at increased risk of diabetes based on data from an earlier pilot study ${ }^{46}$. Treatment will continue for one year with follow-up for the development of diabetes for 4 years.

\section{TERTIARY PREVENTION}

It has long been recognized that most individuals presenting with T1D have little residual insulin secretion (as measured by C-peptide secretion) at the time of diagnosis ${ }^{47}, 48$. However, in the weeks to months after diagnosis and initiation of insulin treatment, there can be substantial recovery of $\beta$ cell function with falling insulin requirements, increasing C-peptide concentrations and relatively easily controlled blood glucose levels ${ }^{47}, 48$. This "honeymoon" or remission period of diabetes may last from weeks to months and occasionally years ${ }^{49}$. The honeymoon period is believed to be the result of the recovery of residual $\beta$ cells unable to cope with the metabolic demands of the body. With institution of insulin treatment and reestablishment of glycemic control, these cells recover their capacity for insulin secretion only to be finally destroyed by the underlying autoimmune process. In addition, changes in insulin sensitivity probably also play a role in the expression of the honeymoon period, with decreased sensitivity at the time of diagnosis due to the hyperglycemia with improvement after establishment of metabolic control ${ }^{50}$. 
The ability to measure C-peptide concentrations in those receiving insulin therapy allows an accurate assessment of residual $\beta$ cell function and can be used as a marker of the efficacy of therapeutic intervention ${ }^{51}$ Prolongation of the honeymoon period has the potential to have significant beneficial effects in those with T1D. Metabolic control is much easier to establish in the presence of some residual insulin secretion. As a result, long-term diabetes-related complications are significantly less prevalent in those with residual insulin secretion. This was well demonstrated in the Diabetes Control and Complications Trial, in which those subjects with sustained C-peptide production were found to have rates of nephropathy, retinopathy and hypoglycemia that were half that found in those without any residual insulin ${ }^{52}$. The population of newly diagnosed T1D patients therefore represents an important group for future study of promising new interventions. Therapies that can safely maintain endogenous insulin secretion in the longer term would represent an important clinical advance.

Several agents, including, cyclosporine, azathioprine and prednisone, were studied in the 1980 's for their efficacy in maintaining insulin production after the diagnosis of diabetes ${ }^{53-56}$. Some beneficial effects were observed, but toxicity concerns made further use of these agents unfavorable. More recently, a number of immunomodulatory monoclonal antibodies have been studied. The monoclonal antibody hOKT3 $\gamma 1$ (Ala-Ala), interferes with $\mathrm{T}$ cell activation by binding the $\mathrm{T}$ cell receptor, $\mathrm{CD} 3^{57}$. Herold et al showed that this modified anti-CD3 monoclonal antibody maintained C-peptide production over two years after one course of administration in newly diagnosed patients within 6 weeks of diagnosis ${ }^{58,59}$. A reduction in $\mathrm{HbA1c}$ and lower insulin doses were found the in treated group when compared to the untreated group. A European multicenter trial showed that a single course of a very similar modified anti-CD3 antibody, ChAglyCD3, in newly diagnosed patients resulted in higher C-peptide production and reduced insulin doses for 18 months following treatment when compared to placebo ${ }^{60}$. These results were most pronounced among patients with C-peptide production at or above $50^{\text {th }}$ percentile. Another study of this modified CD3 molecule has recently completed enrollment through the Immune Tolerance Network. In this study, new onset subjects between 3 and 30 years of age within 8 weeks of diagnosis will receive 2 doses of hOKT3 1 (Ala-Ala), one at the initiation of the study and a second dose one year later. The study will follow $\mathrm{C}$-peptide production over 2 years from the initiation of treatment. In addition, the manufacturers of both of these modified CD3 molecules are sponsoring trials of these agents, the DEFEND-1 and Protégé studies, in recent onset patients.

The TrialNet study group is carrying out a number of trials in individuals newly diagnosed with T1D. The first such TrialNet study assessed the role of mycophenolate mofetil (MMF) and dacluzimab (DZB) in maintaining C-peptide production Both MMF and DZB have been shown to be effective in transplantation regimens and are well characterized and tolerated. This study was stopped early when analysis of C-peptide production at one year after diagnosis revealed no difference between the groups receiving both drugs or placebo.

TrialNet is also investigating the use of the anti-B lymphocyte monoclonal antibody, Rituximab, in preserving C-peptide production in 8 to 40 year olds with new onset diabetes. Rituximab depletes mature B cells thereby reducing antigen presentation to $\mathrm{T}$ cells. It has been shown to be effective in other autoimmune diseases including lupus and rheumatoid arthritis ${ }^{61} .87$ subjects were randomized to this study with results available in mid-2009.

CTLA-4, a costimulatory molecule expressed on $\mathrm{T}$ cells is an important negative regulator of T cell activation. CTLA-4 Ig, a monoclonal antibody that binds to the costimulatory molecules CD80 and CD86, blocking the costimulation that is required for full $\mathrm{T}$ cell activation. This antibody is approved for use in rheumatoid arthritis. In the ongoing TrialNet study, CTLA-4 Ig (Abatacept) is being used in a placebo-controlled study in new onset subjects. Treatment is being given to 112 subjects with $2 / 3$ of subjects receiving active therapy and $1 / 3$ receiving 
placebo infusions over 2 years with recruitment completed in 2009 and results expected in 2011.

Glutamic acid decarboxylase (GAD) is an important antigen in type 1 diabetes. Animal studies have shown that administration of GAD to induce immune tolerance can prevent diabetes ${ }^{62}$. A recent study showed that two doses of GAD formulated in alum given within 6 months of diagnosis slowed the fall of C-peptide production over the first 30 months after initiation of therapy ${ }^{63}$. This study involved 70 subjects between the ages of 10 and 18 with fasting C-peptide greater than $0.1 \mathrm{nmol} / \mathrm{L}$. TrialNet has just launched a trial of 3 or 2 injections of GAD in alum versus placebo in 126 new onset subjects that will include children as young as 3 . The primary endpoint of this study will be C-peptide production at one year after initiation of treatment.

A small randomized placebo-controlled pilot study of the anti-tumor necrosis factor drug, etanercept, was recently reported ${ }^{64}$. The drug was given by subcutaneous injection twice weekly for 24 weeks in 18 children within 4 weeks of diagnosis. C-peptide production was significantly greater in the treatment group with lower HbA1c and smaller insulin doses. Other interventions currently under investigation or planned for study in this patient population are anakinra, thymoglobulin, anti-thymocyte globulin, GAD/lansprazole/sitagliptin, efalizumab, intensive metabolic control, and atorvastatin. Table 1 lists active studies and their eligibility criteria.

\section{“Curing" established T1D}

Once full-blown T1D has developed, immune interventions are unlikely to be effective since the vast majority of $\beta$ cells have been destroyed. At this stage, effective interventions would include $\beta$ cell implantation either as part of pancreatic or islet cell transplantation, gene therapy using implanted cells capable of producing insulin in response to glycemia, or stem cell-derived $\beta$ cells. Pancreatic transplantation has been successfully applied, particularly in combination with kidney transplantation necessitated by diabetes-related end stage renal failure. The paucity of donors and the need for lifelong immune suppression to prevent organ rejection have limited the application of these transplants. Islet cell transplantation enjoyed a period of success when investigators in Edmonton were able to show prolonged graft survival and an insulin free period. However, limited supply of islets, side effects of the immunosuppression and eventual return to insulin dependence, all challenge the ability of this approach to impact broadly. Genetic engineering and stem cell biology hold out the most hope in the long run for a cure for T1D and elimination of the need to inject insulin. With respect to gene therapy, cells have been created in which insulin secretion is possible. However it is produced in small amounts and unregulated by blood sugar concentrations. Stem cells are currently under intensive evaluation; however, successful therapy for diabetes and other immune disorders remains elusive.

\section{References}

1. Devendra D, Liu E, Eisenbarth GS, Devendra D, Liu E, Eisenbarth GS. Type 1 diabetes: recent developments. BMJ Mar 27;2004 328(7442):750-754. [PubMed: 15044291]

2. Eisenbarth GS. Type I diabetes mellitus. A chronic autoimmune disease. The New England Journal of Medicine May 22;1986 314(21):1360-1368. [PubMed: 3517648]

3. Akerblom HK, Vaarala O, Hyoty H, Ilonen J, Knip M. Environmental factors in the etiology of type 1 diabetes. American Journal of Medical Genetics May 30;2002 115(1):18-29. [PubMed: 12116173]

4. Helgason T, Jonasson MR. Evidence for a food additive as a cause of ketosis-prone diabetes. Lancet Oct 3;1981 2(8249):716-720. [PubMed: 6116858]

5. Thorsdottir I, Ramel A. Dietary intake of 10- to 16-year-old children and adolescents in central and northern Europe and association with the incidence of type 1 diabetes. Ann Nutr Metab 2003;47(6): 267-275. [PubMed: 14520022] 
6. Vaarala O, Knip M, Paronen J, et al. Cow's milk formula feeding induces primary immunization to insulin in infants at genetic risk for type 1 diabetes. Diabetes Jul;1999 48(7):1389-1394. [PubMed: 10389843]

7. Virtanen SM, Laara E, Hypponen E, et al. Cow's milk consumption, HLA-DQB1 genotype, and type 1 diabetes: a nested case-control study of siblings of children with diabetes. Childhood diabetes in Finland study group. Diabetes Jun;2000 49(6):912-917. [PubMed: 10866042] [erratum appears in Diabetes 2000 Sep;49(9):1617].

8. Barker JM, Yu J, Yu L, et al. Autoantibody "subspecificity" in type 1 diabetes: risk for organ-specific autoimmunity clusters in distinct groups. Diabetes Care Apr;2005 28(4):850-855. [PubMed: 15793184]

9. Daneman D. State of the world's children with diabetes. Pediatric Diabetes Apr;2009 10(2):120-126. [PubMed: 19175511]

10. International Diabetes Federation. Diabetes Atlas, Third Edition. Vol. Third ed.. Brussels: 2006.

11. Tuomilehto J, Karvonen M, Pitkaniemi J, et al. Record-high incidence of Type I (insulin-dependent) diabetes mellitus in Finnish children. The Finnish Childhood Type I Diabetes Registry Group. Diabetologia Jun;1999 42(6):655-660. [PubMed: 10382584]

12. Raymond NT, Jones JR, Swift PG, et al. Comparative incidence of Type I diabetes in children aged under 15 years from South Asian and White or Other ethnic backgrounds in Leicestershire, UK, 1989 to 1998. Diabetologia Oct;2001 44(Suppl 3):B32-36. [PubMed: 11724414]

13. Kondrashova A, Reunanen A, Romanov A, et al. A six-fold gradient in the incidence of type 1 diabetes at the eastern border of Finland. Annals of Medicine 2005;37(1):67-72. [PubMed: 15902849]

14. Gillespie KM, Bain SC, Barnett AH, et al. The rising incidence of childhood type 1 diabetes and reduced contribution of high-risk HLA haplotypes. Lancet Nov 6-12;2004 364(9446):1699-1700. [PubMed: 15530631]

15. Redondo MJ, Eisenbarth GS. Genetic control of autoimmunity in Type I diabetes and associated disorders. Diabetologia May;2002 45(5):605-622. [PubMed: 12107741]

16. Atkinson MA, Eisenbarth GS. Type 1 diabetes: new perspectives on disease pathogenesis and treatment. Lancet Jul 21;2001 358(9277):221-229. [PubMed: 11476858]

17. Achenbach P, Bonifacio E, Koczwara K, Ziegler AG. Natural history of type 1 diabetes. Diabetes Dec;2005 54(Suppl 2):S25-31. [PubMed: 16306336]

18. Huber A, Menconi F, Corathers S, et al. Joint genetic susceptibility to type 1 diabetes and autoimmune thyroiditis: from epidemiology to mechanisms. Endocr Rev Oct;2008 29(6):697-725. [PubMed: 18776148]

19. Barker JM. Clinical review: Type 1 diabetes-associated autoimmunity: natural history, genetic associations, and screening. The Journal of Clinical Endocrinology and Metabolism Apr;2006 91(4): 1210-1217. [PubMed: 16403820]

20. Cooper JD, Smyth DJ, Smiles AM, et al. Meta-analysis of genome-wide association study data identifies additional type 1 diabetes risk loci. Nature Genetics Dec;2008 40(12):1399-1401. [PubMed: 18978792]

21. Ball TM, Castro-Rodriguez JA, Griffith KA, Holberg CJ, Martinez FD, Wright AL. Siblings, daycare attendance, and the risk of asthma and wheezing during childhood. New England Journal of Medicine Aug 24;2000 343(8):538-543. [PubMed: 10954761]

22. Betts P, Mulligan J, Ward P, Smith B, Wilkin T. Increasing body weight predicts the earlier onset of insulin-dependant diabetes in childhood: testing the 'accelerator hypothesis' (2). Diabetic Medicine Feb;2005 22(2):144-151. [PubMed: 15660730]

23. Daneman D. Is the 'Accelerator Hypothesis' worthy of our attention? Diabetic Medicine Feb;2005 22(2):115-117. [PubMed: 15660726][see comment][comment]

24. Gale EA, Gale EAM. A missing link in the hygiene hypothesis? Diabetologia Apr;2002 45(4):588594. [PubMed: 12032638]

25. Kaila B, Taback SP. The effect of day care exposure on the risk of developing type 1 diabetes: a metaanalysis of case-control studies. Diabetes Care Aug;2001 24(8):1353-1358. [PubMed: 11473069]

26. von Mutius E, Martinez FD, Fritzsch C, Nicolai T, Reitmeir P, Thiemann HH. Skin test reactivity and number of siblings. BMJ Mar 12;1994 308(6930):692-695. [PubMed: 8142793] 
27. Wilkin TJ. The accelerator hypothesis: weight gain as the missing link between Type I and Type II diabetes. Diabetologia Jul;2001 44(7):914-922. [PubMed: 11508279][see comment]

28. Group TS. The Environmental Determinants of Diabetes in the Young (TEDDY) Study. Annals of the New York Academy of Sciences Dec;2008 1150:1-13.

29. Merriman TR, Merriman TR. Type 1 diabetes, the A1 milk hypothesis and vitamin D deficiency. Diabetes Res Clin Pract Feb;2009 83(2):149-156. [PubMed: 19100644]

30. Group TS. Study design of the Trial to Reduce IDDM in the Genetically at Risk (TRIGR). Pediatric Diabetes Jun;2007 8(3):117-137. [PubMed: 17550422]

31. Chase HP, Lescheck E, Rafkin-Mervis L, et al. Nutritional Intervention to Prevent (NIP) Type 1 Diabetes A Pilot Trial. ICAN: Infant, Child, \& Adolescent Nutrition April 1;2009 1(2):98-107.2009

32. Norris JM, Yin X, Lamb MM, et al. Omega-3 polyunsaturated fatty acid intake and islet autoimmunity in children at increased risk for type 1 diabetes. JAMA Sep 26;2007 298(12):1420-1428. [PubMed: 17895458]

33. Schmid S, Buuck D, Knopff A, Bonifacio E, Ziegler AG. BABYDIET, a feasibility study to prevent the appearance of islet autoantibodies in relatives of patients with Type 1 diabetes by delaying exposure to gluten. Diabetologia Jun;2004 47(6):1130-1131. [PubMed: 15168019]

34. Norris JM, Barriga K, Klingensmith G, et al. Timing of initial cereal exposure in infancy and risk of islet autoimmunity. JAMA Oct 1;2003 290(13):1713-1720. [PubMed: 14519705]

35. Moro JR, Iwata M, von Andriano UH, Moro JR, Iwata M, von Andriano UH. Vitamin effects on the immune system: vitamins A and D take centre stage. Nature Rev Immunol Sep;2008 8(9):685-698. [PubMed: 19172691]

36. Zipitis CS, Akobeng AK. Vitamin D supplementation in early childhood and risk of type 1 diabetes: a systematic review and meta-analysis. Arch Dis Child Jun;2008 93(6):512-517. [PubMed: 18339654]

37. Wenzlau JM, Juhl K, Yu L, et al. The cation efflux transporter ZnT8 (Slc30A8) is a major autoantigen in human type 1 diabetes. Proceedings of the National Academy of Sciences of the United States of America Oct 23;2007 104(43):17040-17045. [PubMed: 17942684]

38. Verge CF, Gianani R, Kawasaki E, et al. Number of autoantibodies (against insulin, GAD or ICA512/ IA2) rather than particular autoantibody specificities determines risk of type I diabetes. Journal of Autoimmunity 1996;9(3):379-383. [PubMed: 8816974]

39. Sosenko JM, Palmer JP, Greenbaum CJ, et al. Patterns of metabolic progression to type 1 diabetes in the Diabetes Prevention Trial-Type 1. Diabetes Care Mar;2006 29(3):643-649. [PubMed: 16505520]

40. Mahon JL, Sosenko JM, Rafkin-Mervis L, et al. The TrialNet Natural History Study of the Development of Type 1 Diabetes: objectives, design, and initial results. Pediatric Diabetes Apr;2009 10(2):97-104. [PubMed: 18823409]

41. Gale EA, Bingley PJ, Emmett CL, Collier T. European Nicotinamide Diabetes Intervention Trial (ENDIT): a randomised controlled trial of intervention before the onset of type 1 diabetes. Lancet Mar 20;2004 363(9413):925-931. [PubMed: 15043959]

42. Effects of insulin in relatives of patients with type 1 diabetes mellitus. The New England Journal of Medicine May 30;2002 346(22):1685-1691. [PubMed: 12037147]

43. Skyler JS, Krischer JP, Wolfsdorf J, et al. Effects of oral insulin in relatives of patients with type 1 diabetes: The Diabetes Prevention Trial--Type 1. Diabetes Care May;2005 28(5):1068-1076. [PubMed: 15855569]

44. Nanto-Salonen K, Kupila A, Simell S, et al. Nasal insulin to prevent type 1 diabetes in children with HLA genotypes and autoantibodies conferring increased risk of disease: a double-blind, randomised controlled trial. Lancet Nov 15;2008 372(9651):1746-1755. [PubMed: 18814906]

45. Achenbach P, Barker J, Bonifacio E, et al. Modulating the natural history of type 1 diabetes in children at high genetic risk by mucosal insulin immunization. Curr Diab Rep Apr;2008 8(2):87-93. [PubMed: 18445349]

46. Harrison LC, Honeyman MC, Steele CE, et al. Pancreatic beta-cell function and immune responses to insulin after administration of intranasal insulin to humans at risk for type 1 diabetes. Diabetes Care Oct;2004 27(10):2348-2355. [PubMed: 15451899] 
47. Bonfanti R, Bazzigaluppi E, Calori G, et al. Parameters associated with residual insulin secretion during the first year of disease in children and adolescents with Type 1 diabetes mellitus. Diabetic Medicine 1998;15(10):844-850. [PubMed: 9796885]

48. Sochett EB, Daneman D, Clarson C, Ehrlich RM. Factors affecting and patterns of residual insulin secretion during the first year of type 1 (insulin-dependent) diabetes mellitus in children. Diabetologia 1987;30(7):453-459. [PubMed: 3311859]

49. Pozzilli P, Manfrini S, Buzzetti R, et al. Glucose evaluation trial for remission (GETREM) in type 1 diabetes: a European multicentre study. Diabetes Res Clin Pract Jun;2005 68(3):258-264. [PubMed: 15936469]

50. Yki-Jarvinen H, Koivisto VA. Natural course of insulin resistance in type I diabetes. New England Journal of Medicine 1986;315(4):224-230. [PubMed: 3523247]

51. Palmer JP, Fleming GA, Greenbaum CJ, et al. C-peptide is the appropriate outcome measure for type 1 diabetes clinical trials to preserve beta-cell function: report of an ADA workshop, 21-22 October 2001. Diabetes Jan;2004 53(1):250-264. [PubMed: 14693724] [erratum appears in Diabetes. 2004 Jul;53(7):1934]

52. Steffes MW, Sibley S, Jackson M, et al. Beta-cell function and the development of diabetes-related complications in the diabetes control and complications trial. Diabetes Care Mar;2003 26(3):832836. [PubMed: 12610045]

53. The Canadian-European Randomized Control Trial Group. Cyclosporin-induced remission of IDDM after early intervention. Association of $1 \mathrm{yr}$ of cyclosporin treatment with enhanced insulin secretion. Diabetes Nov;1988 37(11):1574-1582. [PubMed: 2903105]

54. Feutren G, Papoz L, Assan R, et al. Cyclosporin increases the rate and length of remissions in insulindependent diabetes of recent onset. Results of a multicentre double-blind trial. Lancet Jul 19;1986 2 (8499):119-124. [PubMed: 2873396]

55. Harrison LC, Colman PG, Dean B, Baxter R, Martin FI. Increase in remission rate in newly diagnosed type I diabetic subjects treated with azathioprine. Diabetes Dec;1985 34(12):1306-1308. [PubMed: 3905463]

56. Silverstein J, Maclaren N, Riley W, Spillar R, Radjenovic D, Johnson S. Immunosuppression with azathioprine and prednisone in recent-onset insulin-dependent diabetes mellitus. The New England Journal of Medicine Sep 8;1988 319(10):599-604. [PubMed: 3045545]

57. Chatenoud L, Bluestone JA, Chatenoud L, Bluestone JA. CD3-specific antibodies: a portal to the treatment of autoimmunity. Nature Rev Immunol Aug;2007 7(8):622-632. [PubMed: 17641665]

58. Herold KC, Gitelman SE, Masharani U, et al. A single course of anti-CD3 monoclonal antibody hOKT3gamma1(Ala-Ala) results in improvement in C-peptide responses and clinical parameters for at least 2 years after onset of type 1 diabetes. Diabetes Jun;2005 54(6):1763-1769. [PubMed: 15919798]

59. Herold KC, Hagopian W, Auger JA, et al. Anti-CD3 monoclonal antibody in new-onset type 1 diabetes mellitus. New England Journal of Medicine May 30;2002 346(22):1692-1698. [PubMed: 12037148]

60. Keymeulen B, Vandemeulebroucke E, Ziegler AG, et al. Insulin needs after CD3-antibody therapy in new-onset type 1 diabetes. The New EnglandJjournal of Medicine Jun 23;2005 352(25):25982608.

61. Levesque MC, St Clair EW, Levesque MC, St Clair EW. B cell-directed therapies for autoimmune disease and correlates of disease response and relapse. J Allergy Clin Immunol Jan;2008 121(1):1321. [PubMed: 18206502]quiz 22-13

62. Tisch R, Wang B, Serreze DV. Induction of glutamic acid decarboxylase 65-specific Th2 cells and suppression of autoimmune diabetes at late stages of disease is epitope dependent. Journal of Immunology 1999;163(3):1178-1187.

63. Ludvigsson J, Faresjo M, Hjorth M, et al. GAD treatment and insulin secretion in recent-onset type 1 diabetes. New England Journal of Medicine Oct 30;2008 359(18):1909-1920. [PubMed: 18843118]

64. Mastrandrea L, Yu J, Behrens T, et al. Etanercept Treatment in Children with New Onset Type 1 Diabetes: Pilot Randomized, Placebo-Controlled, Double Blind Study. Diabetes Care. 2009 published online on April 14, 2009 as 10.2337/dc09-0054 


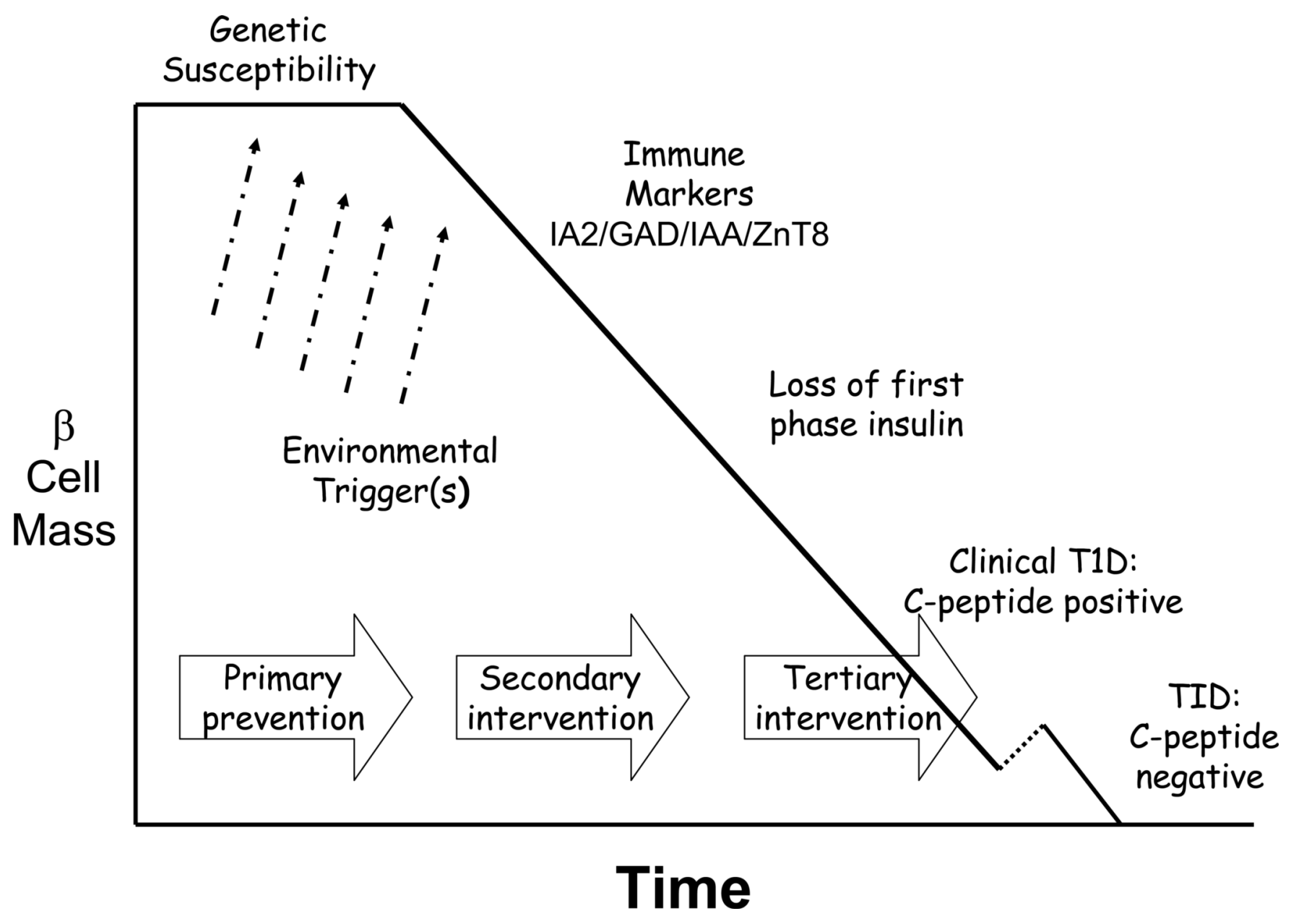

Figure 1.

The Natural History of Type 1 Diabetes 


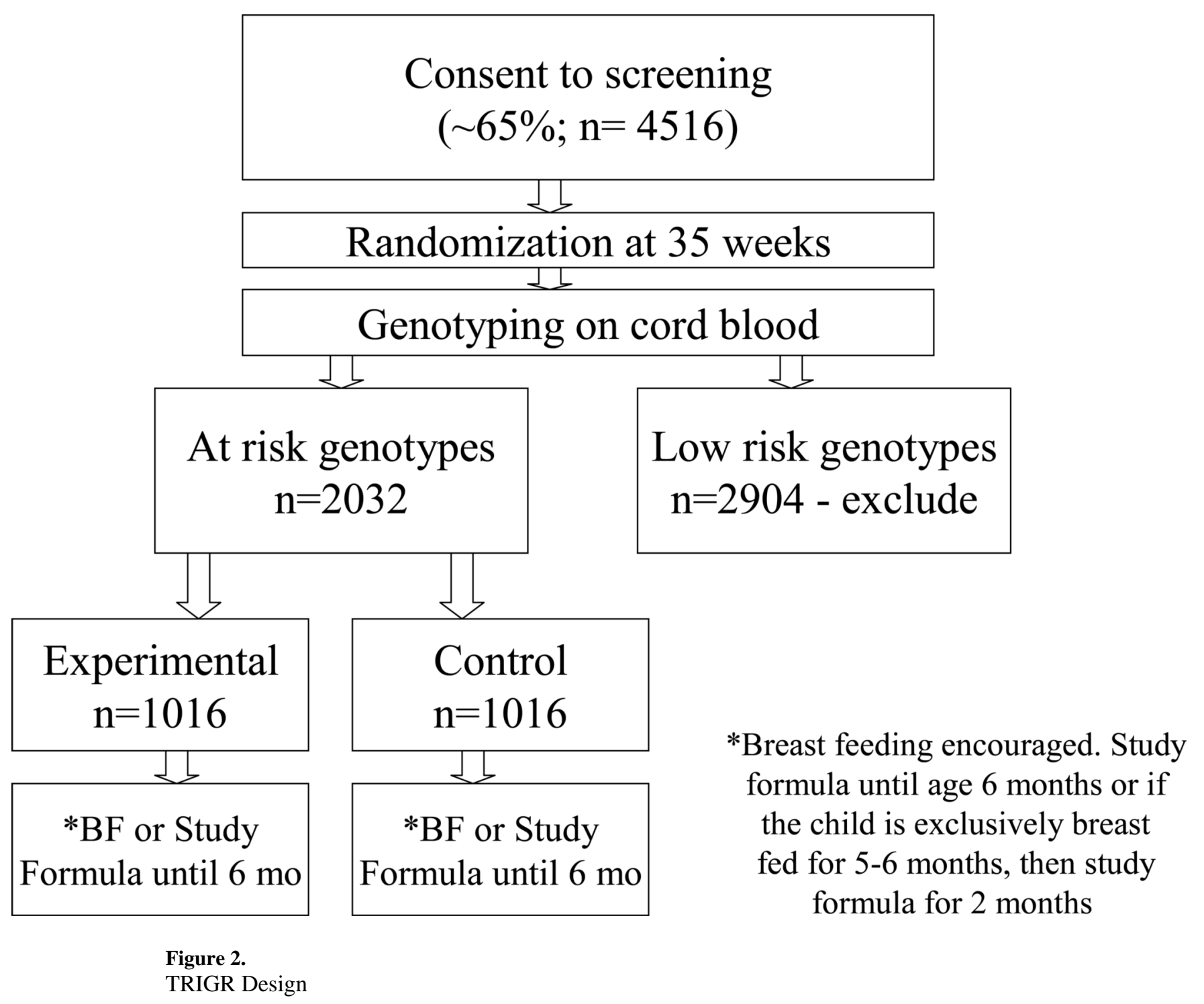


Table 1

Active Studies with Ongoing Enrollment and their Eligibility Criteria

Natural History Study of the Development of Type 1 Diabetes - Do not have diabetes

Sponsor: TrialNet Study Group - $\quad \cdot 1$ to 45 years of age and first degree relative of a person with T1D

列 3 to 45 years of age with relative with type 1 diabetes

Type 1 Diabetes Mellitus $\quad$ - insulin autoantibodies and one other diabetes autoantibody

Sponsor: TrialNet Study Group - $\quad$ normal glucose tolerance

Effects of Recombinant Human Glutamic Acid Decarboxylase - $3 *$ to 45 years of age

Formulated in Alum on the Progression of Type 1 Diabetes in • within 3 months of diagnosis of diabetes

New Onset Subjects

Sponsor: TrialNet Study Group - $\quad$ - stimulated C-peptide levels $\geq 0.2 \mathrm{pmol} / \mathrm{mL}$

Study of Thymoglobulin to Arrest Newly Diagnosed Type $1 \quad \cdot 12$ to 35 years of age

Diabetes (START)

- diagnosis of diabetes within the 12 weeks prior to study entry
positive for one or more autoantibodies (anti-glutamic acid decarboxylase [GAD], anti-

insulin, or IA-2 autoantibodies)

- stimulated C-peptide level $>0.4 \mathrm{pmol} / \mathrm{mL}$

Trial of Intranasal Insulin in Children and Young Adults at Risk • age 4-30 years if first-degreeof a person with T1D

of Type 1 Diabetes(INIT II)

Sponsor: Melbourne Health/Diabetes Vaccine Development

Centre -

- age 4-20 years if second-degree relative of a person with T1D

\begin{tabular}{l|l} 
• first phase insulin relase above threshold \\
\hline
\end{tabular}

Primary Intervention with Oral/Nasal Isulin for Prevention of - between 18 months and 7 years

Type 1 Diabetes in Infants at High Genetic Risk to Develop • high risk HLA genotype

Type 1 Diabetes (Pre-POINT)

Sponsor: Juvenile Diabetes Research Foundation

Phase 3 Trial of Otelixizumab for Adults With Newly

Diagnosed Type 1 Diabetes Mellitus (Autoimmune):

DEFEND-1

Sponsor: Tolerx/Juvenile Diabetes Research Foundation

- sibling or both parents with diabetes

- does not have diabetes or diabets autoantibodies

- ages 18-35 years

- diagnosis of diabetes mellitus, no more than 90 days between diagnosis and

administration of study drug

$\mathrm{L}$

L

- positive for one or both of the following antibodies: islet-cell autoantibodies (anti-IA2 and/or glutamic acid decarboxvlase (GAD) autoantibodies

The Protégé Study - Clinical Trial of Teplizumab in Children $\bullet 8$ to 35 years

and Adults With Recent-Onset Type 1 Diabetes Mellitus $\quad \cdot$ diagnosis of type 1 diabetes mellitus within 12 weeks

Sponsor: MacroGenics

- detectable fasting or stimulated C-peptide level

- positive for: islet-cell autoantibodies (ICA512/IA-2), glutamic acid decarboxylase

autoantibodies, or insulin autoantibodies (if present during first 2 weeks, but not beyond

2 weeks, of insulin treatment) 